Article

\title{
Cross-Species BAC Mapping Highlights Conservation of Chromosome Synteny across Dragon Lizards (Squamata: Agamidae)
}

\author{
Shayer Mahmood Ibney Alam ${ }^{1, *(\mathbb{D})}$, Marie Altmanová ${ }^{2}{ }^{(0)}$, Tulyawat Prasongmaneerut ${ }^{3}$, \\ Arthur Georges ${ }^{1}\left(\mathbb{D}\right.$, Stephen D. Sarre ${ }^{1}(\mathbb{D})$, Stuart V. Nielsen ${ }^{4,5}$, Tony Gamble ${ }^{4,6,7}$, \\ Kornsorn Srikulnath ${ }^{3}$ (D) Michail Rovatsos ${ }^{2}\left(\mathbb{D}\right.$, Lukáš Kratochvíl ${ }^{2}$ and Tariq Ezaz ${ }^{1, *(D)}$ \\ 1 Institute for Applied Ecology, University of Canberra, Bruce, ACT 2617, Australia; \\ georges@aerg.canberra.edu.au (A.G.); stephen.sarre@canberra.edu.au (S.D.S.) \\ 2 Department of Ecology, Faculty of Science, Charles University, 12844 Prague, Czech Republic; \\ marie.altmanova@natur.cuni.cz (M.A.); michail.rovatsos@natur.cuni.cz (M.R.); \\ lukas.kratochvil@natur.cuni.cz (L.K.) \\ 3 Laboratory of Animal Cytogenetics \& Comparative Genomics, Department of Genetics, Faculty of Science, \\ Kasetsart University, Bangkok 10900, Thailand; tulyawat.pr@ku.th (T.P.); kornsorn.s@ku.ac.th (K.S.) \\ 4 Department of Biological Sciences, Marquette University, Milwaukee, WI 53233, USA; \\ stunie@gmail.com (S.V.N.); anthony.gamble@marquette.edu (T.G.) \\ 5 Division of Herpetology, Florida Museum of Natural History, University of Florida, Gainesville, \\ FL 32611, USA \\ 6 Milwaukee Public Museum, 800 W. Wells St., Milwaukee, WI 53233, USA \\ 7 Bell Museum of Natural History, University of Minnesota, 2088 Larpenteur Ave. W., St. Paul, \\ MN 55113, USA \\ * Correspondence: shayer.alam@canberra.edu.au (S.M.I.A.); tariq.ezaz@canberra.edu.au (T.E.)
}

Received: 18 May 2020; Accepted: 22 June 2020; Published: 25 June 2020

\begin{abstract}
Dragon lizards (Squamata: Agamidae) comprise about 520 species in six subfamilies distributed across Asia, Australasia and Africa. Only five species are known to have sex chromosomes. All of them possess ZZ/ZW sex chromosomes, which are microchromosomes in four species from the subfamily Amphibolurinae, but much larger in Phrynocephalus vlangalii from the subfamily Agaminae. In most previous studies of these sex chromosomes, the focus has been on Australian species from the subfamily Amphibolurinae, but only the sex chromosomes of the Australian central bearded dragon (Pogona vitticeps) are well-characterized cytogenetically. To determine the level of synteny of the sex chromosomes of $P$. vitticeps across agamid subfamilies, we performed cross-species two-colour FISH using two bacterial artificial chromosome (BAC) clones from the pseudo-autosomal regions of P. vitticeps. We mapped these two BACs across representative species from all six subfamilies as well as two species of chameleons, the sister group to agamids. We found that one of these BAC sequences is conserved in macrochromosomes and the other in microchromosomes across the agamid lineages. However, within the Amphibolurinae, there is evidence of multiple chromosomal rearrangements with one of the BACs mapping to the second-largest chromosome pair and to the microchromosomes in multiple species including the sex chromosomes of $P$. vitticeps. Intriguingly, no hybridization signal was observed in chameleons for either of these BACs, suggesting a likely agamid origin of these sequences. Our study shows lineage-specific evolution of sequences/syntenic blocks and successive rearrangements and reveals a complex history of sequences leading to their association with important biological processes such as the evolution of sex chromosomes and sex determination.
\end{abstract}

Keywords: agamid lizards; sex chromosomes; BACs; synteny; evolution; FISH 


\section{Introduction}

Reptiles are well known for their diverse modes of sex determination and sex chromosomes [1,2]. They exhibit large variability in the degree of differentiation of sex chromosomes ranging from homomorphic to heteromorphic in structure [2-5]. Squamate reptiles (lizards, snakes and amphisbaenians) are the most diverse reptile group in terms of species diversity and mode of sex determination $[1,6]$. The variability seen among squamate sex chromosomes suggests that sex chromosome and sex determination systems have evolved independently many times. Non-homologous sex chromosomes have been reported even among relatively closely related species $[2,5,7]$. The same parts of the genome (i.e., homologous regions) have been found to play the role of sex chromosomes in different vertebrate taxa [5,8-11]. A high degree of synteny has been observed between birds and squamate reptiles owing to a relative low degree of chromosomal rearrangements in this group [5,12-18]. Temperature-dependent sex determination (TSD), genotypic sex determination (GSD), and GSD with temperature influences between relatively closely related species make squamate lizards an interesting group to study and understand the evolution of sex chromosomes.

Agamid lizards (Squamata: Agamidae), commonly known as dragons in Australasia, are notorious for their variability in forms of sex determination [19-23]. Together with chameleons (Chamaeleonidae), they form the iguanian clade Acrodonta, sister to iguanas (Pleurodonta) [24,25]. Acrodonts are an interesting group in terms of the evolution and diversity of sex determination [7,26,27], while the iguanas have, with one exception (basilisks), conserved XX/XY sex chromosomes [28,29]. There are about 520 currently described agamid species [6] comprising six subfamilies that diverged around 70-120 million years ago [25,30]. Most agamid species are oviparous [6], and the groups includes species with obligate and facultative parthenogenesis [31-33]. Sex determination mode is relatively well studied in a few species from the subfamily Amphibolurinae [7,19], but not in the other five subfamilies (Figure 1), highlighting a significant gap in our understanding of how sex chromosomes evolved in this widespread and chromosomally variable family.

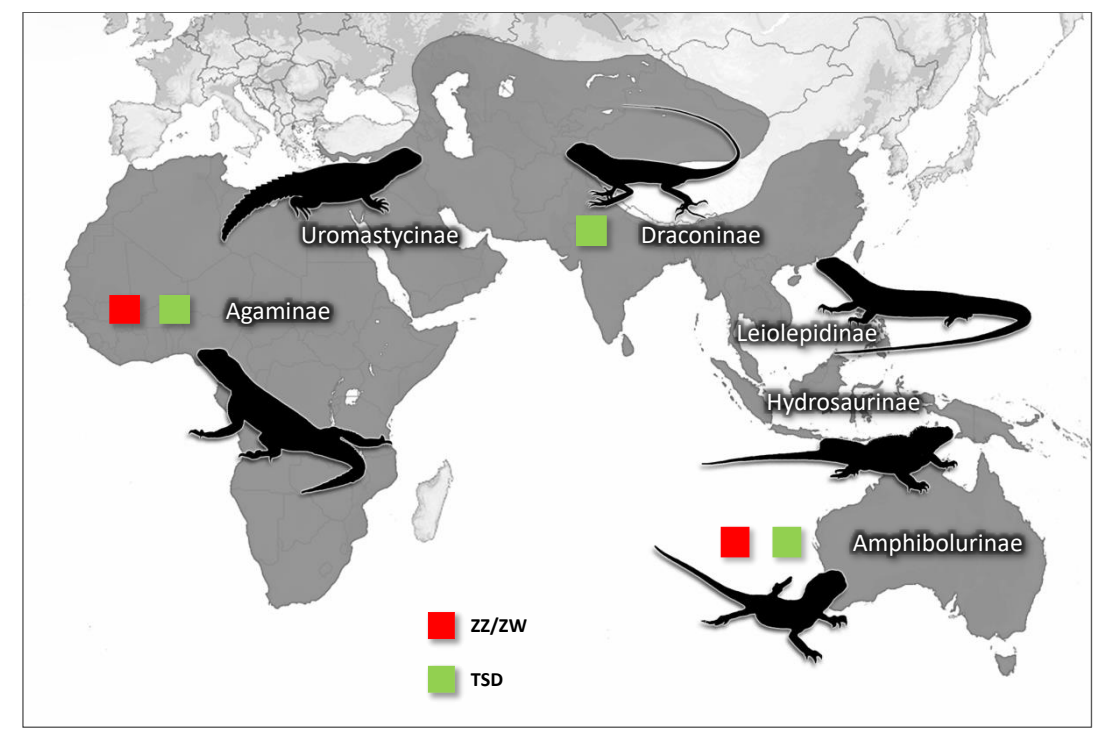

Figure 1. Estimated distribution of the agamid subfamilies together with known sex determination mechanisms $[6,17,20,21,24,31,34-49]$. The species of the subfamily Draconinae are distributed over South and Southeast Asia, Agaminae across Africa and Asia, Amphibolurinae across Australia, Papua New Guinea and Southeast Asia, Hydrosaurinae across Papua New Guinea, the Philippines and Indonesia, Leiolepidinae across Southeast Asia and Uromastycinae across Africa and South Asia. TSD—temperature dependent sex determination, ZZ/ZW—female heterogamety. Obligatory parthenogenesis has been reported in several species of the subfamily Leiolepidinae, although the sex determination system is not known in this lineage. 
Only about one fifth (91 species) of Agamid species have been karyotyped, with diploid chromosome numbers ranging from $2 n=32$ to $2 n=54$ [4,6,50]. Agamids exhibit a diverse array of sex-determination mechanisms that include TSD, GSD and GSD with sex reversal $[1,2,22,39,51]$. Sex chromosomes have only been identified in five species, all with a female heterogametic system (ZZ male/ZW female). Sex chromosomes in an Asian species Phrynocephalus vlangalii from the subfamily Agaminae are macrochromosomes [39], whereas the four Australian species from the subfamily Amphibolurinae, namely, Pogona vitticeps, P. barbata, Diporiphora nobbi and Ctenophorus fordi, have micro sex chromosomes $[7,20]$. The karyotypes of the Australian species are highly conserved, comprising six pairs of macrochromosomes and ten pairs of microchromosomes [35]. Nevertheless, they show considerable evolutionary lability in sex determination mechanisms $[19,52]$ with a number of likely transitions reported within GSD forms and between GSD and TSD [2,7,30,53].

Molecular cytogenetics is a powerful tool for discovering homology and evolutionary trends in reptile sex chromosomes [54,55] and has provided evidence that the sex chromosomes of lizards are extremely varied in terms of morphology and homology [2,5]. The Australian central bearded dragon, Pogona vitticeps, has a well-annotated genome with well-characterized ZZ/ZW sex microchromosomes, homologous to chicken chromosomes 17 and 23 [20,56-60]. Comparative studies based on this and other species have revealed chromosomal rearrangements involving sex chromosomes and transitions in sex chromosomes within the Amphibolurinae [7,61,62], including the rapid evolution of non-homologous $\mathrm{ZW}$ sex chromosomes. Here, we evaluate the synteny of sex chromosomes across the dragons of the family Agamidae using fluorescence in situ hybridization (FISH) [7]. We used two BAC clones (Pv03_L07 and Pv150_H19) derived from P. vitticeps ZW sex chromosomes as probes and hybridized them to the metaphase chromosomes of 14 acrodont taxa (12 agamids from all six subfamilies, and two chameleons), comprising species that span the spectrum of sex determination, including TSD, GSD and obligatory parthenogenesis.

\section{Materials and Methods}

\subsection{Animal and Sample Collection}

In total, 22 individuals of 14 species of acrodont lizards-12 agamids (from six subfamilies) and 2 chamaeleonid species-were chosen for the study (Table 1). Animal collection, handling, sampling and all other relevant procedures for the Australian species (P. vitticeps, Tympanocryptis lineata and Rankinia diemensis) were performed following the Animal Ethics Guidelines of the University of Canberra (approval number CEAE 16-21), with permits issued by the ACT Government (license number LT2017960). Fieldwork conducted for Agama picticauda was under Miami-Dade County Parks and Recreation Scientific Research Permit number 263-2016 and Marquette University IACUC AR-288. Calotes versicolor and Leiolepis reevesii rubritaeniata specimen collection, animal care and procedures were approved by the Animal Experiment Committee, Kasetsart University, Thailand (approval number ACKU61-SCI-021). Phrynocephalus cf. guttatus, Bronchocela cristatella, Leiolepis cf. ngovantrii, Saara loricata and Chamaeleo calyptratus were sampled in collaboration with breeders in Czech Republic. Samples of Hydrosaurus weberi and Trioceros johnstoni were provided by Czech zoological gardens (Zoo Plzeň and Zoopark Zájezd, respectively). All experimental procedures in Czech Republic were approved by the Committee for Animal Welfare of the Ministry of Agriculture of the Czech Republic, permissions No. 29555/2006-30 and 8604/2019-7.

\subsection{Cell Culture and Chromosome Preparation}

Fibroblast cells were cultured from the tail tissues of $P$. vitticeps, T. lineata, R. diemensis and A. picticauda for the cytogenetic analyses. Cells were cultured, and metaphase chromosomes were harvested following the procedures as described by Ezaz et al. [63]. C. versicolor and L. reevesii rubritaeniata cells were also cultured from tail tissues. Cell culture and chromosome harvesting followed the procedures as described by Chaiprasertsri et al. [64]. Mitotic chromosomes of P. cf. 
guttatus, B. cristatella, L. cf. ngovantrii, S. loricata, C. calyptratus, H. weberi and T. johnstoni were obtained by cultivation of leukocytes and the preparation of the cell cultures and chromosome harvesting followed a detailed protocol described in Mazzoleni et al. [65].

Table 1. Results of the bacterial artificial chromosome (BAC) clone fluorescence in situ hybridization (FISH) experiments. SDM = sex determination mechanism, $2 \mathrm{n}=$ diploid chromosome number, $\mathrm{M}+\mathrm{m}=$ number of macrochromosomes and microchromosomes, GSD = genotypic sex determination, $\mathrm{TSD}=$ temperature-dependent sex determination, $\mathrm{UNK}=$ unknown, $\mathrm{OP}=$ unisexuality with obligatory parthenogenesis, qtel-telomeric region of the large arm of a macrochromosome.

\begin{tabular}{|c|c|c|c|c|c|c|}
\hline \multirow{2}{*}{ Taxon } & \multirow{2}{*}{ SDM } & \multirow{2}{*}{$2 n$} & \multirow{2}{*}{$\mathbf{M}+\mathbf{m}$} & \multirow{2}{*}{ Sex } & \multicolumn{2}{|l|}{ Mapping } \\
\hline & & & & & Pv03_L07 & Pv150_H19 \\
\hline \multicolumn{7}{|c|}{$\begin{array}{c}\text { Family: Agamidae } \\
\text { Subfamily Amphibolurinae }\end{array}$} \\
\hline Pogona vitticeps & GSD-ZW & 32 & $12+20$ & $1 \mathrm{~F}$ & 2qtel $+\mathrm{ZW}$ micro sex chromosome & $\begin{array}{l}\text { ZW micro sex } \\
\text { chromosome }\end{array}$ \\
\hline Tympanocryptis lineata & UNK & 32 & $12+20$ & $1 \mathrm{M}, 1 \mathrm{~F}$ & $2 q t e l+1$ pair of micros & 1 pair of micros \\
\hline Rankinia diemensis & UNK & 32 & $12+20$ & $1 \mathrm{M}, 1 \mathrm{~F}$ & $2 q t e l+2$ pairs of micros & 1 pair of micros \\
\hline \multicolumn{7}{|c|}{ Subfamily Agaminae } \\
\hline Agama picticauda & TSD & 44 & $20+24$ & $1 \mathrm{M}, 1 \mathrm{~F}$ & 1qtel & 1 pair of micros \\
\hline Phrynocephalus cf. guttatus & UNK & 46 & $22+24$ & $1 \mathrm{M}, 1 \mathrm{~F}$ & 1qtel & No hybridization \\
\hline \multicolumn{7}{|c|}{ Subfamily Draconinae } \\
\hline Calotes versicolor & TSD & 34 & $12+22$ & $1 \mathrm{M}, 1 \mathrm{~F}$ & 2qtel & 1 pair of micros \\
\hline Bronchocela cristatella & UNK & 34 & $14+20$ & $1 \mathrm{~F}$ & $5 q t e l$ & No hybridization \\
\hline \multicolumn{7}{|c|}{ Subfamily Hydrosaurinae } \\
\hline Hydrosaurus sp. & UNK & 36 & $12+24$ & 1 UNK & No hybridization & 1 pair of micros \\
\hline Hydrosaurus weberi & UNK & 36 & $12+24$ & $1 \mathrm{M}$ & 2qtel & No hybridization \\
\hline \multicolumn{7}{|c|}{ Subfamily Leiolepidinae } \\
\hline Leiolepis reevesii rubritaeniata & UNK & 36 & $12+24$ & $1 \mathrm{~F}$ & 2qtel & 1 pair of micros \\
\hline Leiolepis cf. ngovantrii & OP & 36 & $12+24$ & $1 \mathrm{~F}$ & 2qtel & 1 pair of micros \\
\hline \multicolumn{7}{|c|}{ Subfamily Uromastycinae } \\
\hline Saara loricata & UNK & 36 & $12+24$ & $1 \mathrm{M}, 1 \mathrm{~F}$ & 2qtel & No hybridization \\
\hline \multicolumn{7}{|c|}{ Family: Chamaeleonidae } \\
\hline Chamaeleo calyptratus & $X Y$ & 24 & $12+12$ & $1 \mathrm{M}, 1 \mathrm{~F}$ & No hybridization & No hybridization \\
\hline Trioceros johnstoni & UNK & 36 & $14+22$ & $1 \mathrm{M}, 1 \mathrm{~F}$ & No hybridization & No hybridization \\
\hline
\end{tabular}

\subsection{Fluorescence In Situ Hybridization (FISH) and Image Analysis}

Two P. vitticeps ZW sex chromosome BAC clones (Pv03_L07 and Pv150_H19) from the P. vitticeps Bacterial Artificial Chromosome (BAC) library (6.2x, Amplicon Express, Pullman, WA, USA) [56] were mapped onto the metaphase chromosomes of all 14 species (Table 1). The sex chromosomes of $P$. vitticeps have been found to be highly repetitive in nature [56]. The BAC Pv03_L07 (about 98 kb) contains $41 \%$ of repetitive sequences of which $43 \%$ are non-LTR (long terminal repeat) retrotransposons and includes at least two genes, ZNF135-like and a fragment of ORPRD1 [56]. BAC Pv150_H19 (size not estimated and repeat content not known) contains the NR5A1 gene [59], which is known to play an important role in sex differentiation [59]. These two BAC clones share homologous sequences with chicken chromosome 17 and were chosen because they were previously mapped in few agamid species, and their sequence content is known [59]. The two BACs, Pv03_L07 and Pv150_H19, represent the two ends of $\mathrm{Z}$ and $\mathrm{W}$ chromosomes of $P$. vitticeps. In addition, BAC Pv03_L07 hybridizes onto the telomeric region of the second-largest chromosome (chromosome 2) of P. vitticeps [56,57,59]. The two BAC clones were mapped using FISH, following the protocols described in Ezaz et al. [7] and Young et al. [58].

All slides were observed, and images of metaphases were captured using a Zeiss Axio Scope A1 epifluorescence microscope fitted with a high-resolution microscopy camera AxioCam MRm Rev. 3 (Carl Zeiss Ltd. Oberkochen, Germany). Images were analyzed using Metasystems Isis FISH Imaging System V 5.5.10 software (Metasystems, Altlussheim, Germany).

\section{Results}

In line with the previous observations [56,59,61], the BAC clone Pv03_L07 hybridized onto the Z and $\mathrm{W}$ chromosomes as well as onto the telomeric region of the long arms of the chromosome pair 
2 in P. vitticeps (Figure 2a). This BAC probe hybridized onto the telomeric region of the long arms of the chromosome pair 2 in all species under the subfamilies Amphibolurinae (P. vitticeps, T. lineata and $R$. diemensis; Figure $2 \mathrm{a}-\mathrm{c}$ ), Uromastycinae (S. loricata; Figure $2 \mathrm{~d}$ ) and Leiolepidinae (L. reevesii rubritaeniata and L. cf. ngovantrii; Figure 2e,f). A similar hybridization pattern was also observed in H. weberi (Hydrosaurinae, Figure 2h), but no hybridization signal was detected in Hydrosaurus sp. (Figure $2 \mathrm{~g}$ ). The probe also hybridized onto chromosome 2 in $C$. versicolor from the subfamily Draconinae, (Figure 2i) but onto the fifth-largest chromosome pair in another member of that family, B. cristatella (Figure 2j). Hybridization signals from BAC clone Pv03_L07 were observed in the largest chromosome pair in members of the subfamily Agaminae (A. picticauda and P. cf. guttatus; Figure 2k,1). Additional to chromosome 2, BAC Pv03_L07 only hybridized onto microchromosomes in the subfamily Amphibolurinae (Figure 2a-c), onto one pair in P. vitticeps and T. lineata and two pairs in R. diemensis. In P. vitticeps, the BAC Pv03_L07 hybridization signal varied between $Z$ and $W$ with a brighter signal in the $\mathrm{W}[56,59]$. The only other species in which we observed a similar pattern was $R$. diemensis. In this species, BAC Pv03_L07 hybridized to an additional pair of microchromosomes and the hybridization signals in one pair are brighter than the other. However, no inter-sex pattern variation was observed either in this species.

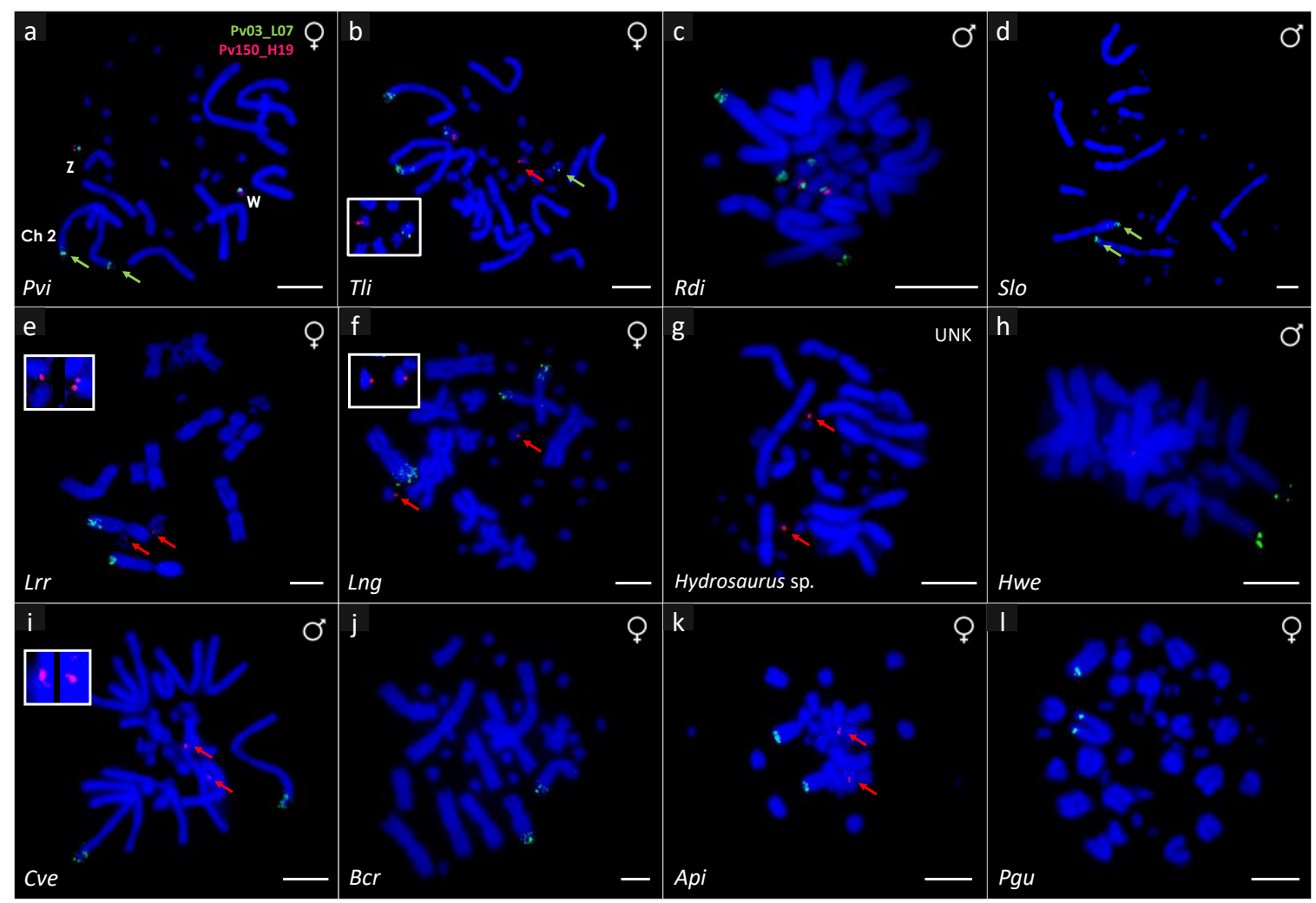

Figure 2. FISH (fluorescence in situ hybridization) using P. vitticeps BAC clones (Pv03_L07 in green and Pv150_H19 in red) on different agamid species. Pvi-P. vitticeps (a); Tli-T. lineata (b); Rdi-R. diemensis (c); Slo—S. loricate (d); Api-A. picticauda (k); Pgu—P. cf. guttatus (1); Cve-C. versicolor (i); Bcr-B. cristatella (j); Lrr-L. reevesii rubritaeniata (e); Lng—L. cf. ngovantrii (f); Hydrosaurus sp. (g); Hwe-H. weberi (h); UNK-unknown sex. Arrows and insets showing very low hybridization signals. Scale bars equal $5 \mu \mathrm{m}$.

The hybridization patterns formed by the BAC probe Pv150_H19 across agamid lizards are presented in Figure 2. This BAC probe hybridized onto the $\mathrm{Z}$ and $\mathrm{W}$ chromosomes of $P$. vitticeps (Figure 2a), as previously observed [57,59]. The hybridization signals from Pv150_H19 co-localized with the signals from Pv03_L07 in this species (Figure 2a) and hybridized onto a pair of microchromosomes 
in all species of the subfamilies Amphibolurinae (P. vitticeps, T. lineata and R. diemensis; Figure 2a-c) and Leiolepidinae (L. reevesii rubritaeniata and L. cf. ngovantrii; Figure 2e,f). However, the hybridization signals were observed in only one species from each of the subfamilies Hydrosaurinae (Hydrosaurus sp.; Figure 2g), Draconinae (C. versicolor; Figure 2i) and Agaminae (A. picticauda; Figure 2k) while no hybridization signal was observed in S. loricata (subfamily Uromastycinae; Figure 2d). Both BAC clones hybridized onto microchromosomes in all species of the subfamily Amphibolurinae (P. vitticeps, T. lineata and R. diemensis; Figure 2a-c). Nevertheless, in T. lineata, the BACs did not colocalize on the same pair of microchromosomes. No inter- or intra-sex variation of the BAC Pv150_H19 hybridization signal was recorded from P. vitticeps [59], nor was variation detected in any of our studied species. No hybridization signal was observed from any of the BAC clones in any of the chameleon species (C. calyptratus and T. johnstoni; Table 1). A summary of the overall BAC mapping is presented in Table 1.

\section{Discussion}

Our data revealed the conservation of macro- and microchromosome specific sequences across Agamidae. The P. vitticeps sex chromosome derived BAC probe Pv03_L07, which hybridizes onto the sex microchromosomes and telomeric region of chromosome 2 in P. vitticeps, hybridized to a pair of macrochromosomes across agamid lineages in all but one species (Hydrosaurus sp.; Figure 2g). This suggests that chromosomal synteny is retained across agamid lineages. In contrast, none of the BACs hybridized to chameleon chromosomes. Together, our findings indicate that the sequence is conserved in macrochromosomes across the Agamidae but has most likely been secondarily lost in the ancestor of Hydrosaurus sp. (Figure 3).

The BAC Pv03_L07 exhibits a conserved hybridization pattern on the telomeric region of macrochromosome 2 in members of the subfamilies Amphibolurinae, Hydrosaurinae, Leiolepidinae and Uromastycinae. However, it is localized in the largest chromosome pair in both members of the subfamily Agaminae, which might represent a synapomorphy. The localization of the hybridization signal of Pv03_L07 on chromosome 5 in B. cristatella suggests a chromosomal rearrangement in its ancestor. Additionally, it hybridizes onto two pairs of microchromosomes in R. diemensis and one pair in T. lineata. Both of those species are representatives of the subfamily Amphibolurinae, and so, these data lend support to the chromosomal rearrangements such as duplication near the telomeric region of ancestral chromosome 2 and successive translocation to microchromosomes as previously reported by Matsubara et al. [61].

The second BAC clone, Pv150_H19, was derived from P. vitticeps Z and W sex chromosomes only, and its sequences are located onto the opposite ends of the $\mathrm{Z}$ and $\mathrm{W}$ micro sex chromosomes in relation to Pv03_L07 (Figure 2a). This probe also showed somewhat conserved distribution in a pair of microchromosomes across the agamid phylogeny. The probe hybridized to all species of Amhibolurinae and Leiolepidinae, to one of two species in Hydrosaurinae, Draconinae and Agaminae and did not hybridize to the only species from Uromastycinae (Figure 3). This suggests a haphazard distribution across the lineages. The absence of signal in S. loricata and presence in all other agamid subfamilies indicate that BAC Pv150_H19 sequence might have evolved after the split of the other lineages from Uromastycinae (Figure 3). The lack of hybridization signal in B. cristatella, P. cf. guttatus and $H$. weberi suggests an independent loss in these three species. Alternatively, there could be a mutation in the target sequence so that the probe was washed away from the less complementary target, and/or shrinkage of the target sequence, so it was no longer detectable. Since BACs are usually predominately composed of repeats which evolve quickly, it is possible that the sequences are still present in all the species but no longer detectable with the approach used. The sequence content of both BACs is enriched on repetitive elements [52,55], which—due to their fast-evolution nature-may have diverged significantly since agamid and chameleon lineages split approximately 90-125 million years ago (MYA) [25,26,62]. Therefore, the homologous sequences might exist in the genome of chameleons but the BACs could not hybridize because of significant divergence from P. vitticeps. (These results must be viewed with some caution, however, as they are based on a limited number of chameleon 
species, which have also been shown to harbour transitions between sex determining systems [27].) Pv150_H19 hybridized to a microchromosome pair in both TSD and GSD species, but we were unable to determine whether these microchromosomes (with Pv150_H19 signals) were sex chromosomes. Nevertheless, since this BAC contains a gene associated with sex differentiation function (NR5A1), it is possible that the microchromosome pair with Pv150_H19 could be a sex chromosome in the GSD species. If so, those same homologous chromosomes could be autosomes in the TSD species while still contributing to the sex-differentiation cascade or pathways. Further investigation is required on this aspect.

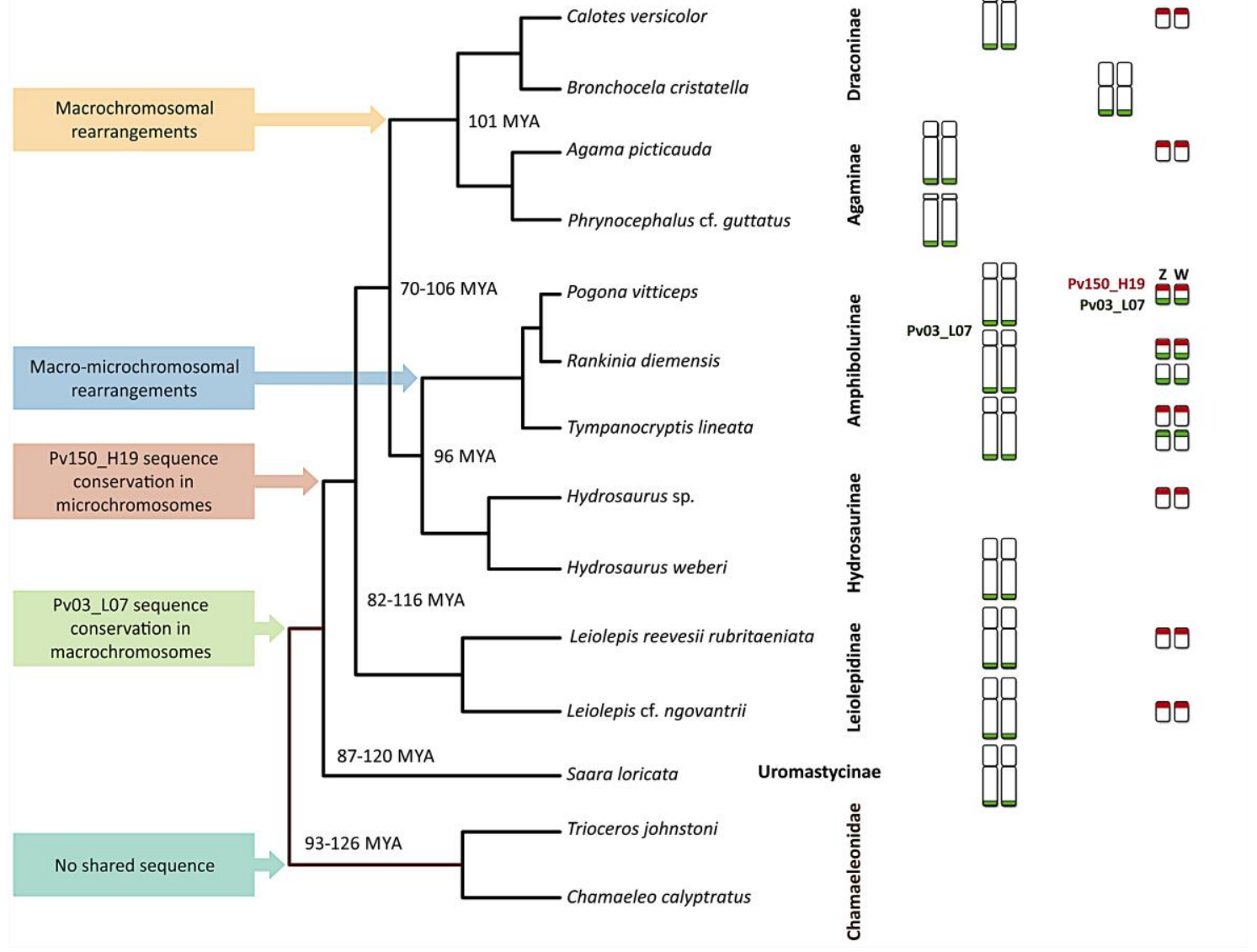

Figure 3. Cross-species chromosome mapping of $P$. vitticeps sex-chromosome-derived BAC probes Pv03_L07 (in green) and Pv150_H19 (in red) highlighting hypothetical evolutionary scenarios of chromosome rearrangements within the subfamilies of Agamidae. Truncated phylogeny (not according to scale) is adopted from Pyron, et al. [24]. Known divergence times are provided in million years ago (MYA) [25,30,66].

The ancestral vertebrate karyotype has remained relatively stable over the last $\sim 370$ million years as large segments of ancestral chromosomes are still retained among all lineages [67]. These segments have been rearranged, but their synteny has been maintained together with increases and decreases of genomic content and genome sizes. Chromosome painting has been used to determine such homologies, as well as rearrangements among and between different reptilian species [8]. For example, karyotype and genome organization have been found to be conserved in monitor lizards (Varanidae) $[18,68]$. Conservation of several homologous syntenic regions has been found to be retained within different groups of fishes [69,70] and birds [71,72] as well. Comparative painting has also revealed chromosome homologies between bird groups [73] and also between vertebrate groups as observed between turtle 
sex chromosomes and amphibian autosomes [74]. The data presented in agamids show that this group has quite conserved karyotypes as well, and many rearrangements can be putatively dated a long time ago (Figure 3). The broad distribution of our Pogona vitticeps derived BAC sequences among agamids indicate that there has been conservation of chromosome segments across agamid lineages. The BAC sequence contained in the BAC Pv150_H19 is largely conserved in microchromosomes across the agamid phylogeny, while the other (BAC Pv03_L07) in macrochromosomes appears to have been only translocated to microchromosomes in the ancestor of the studied members of the subfamily Amphibolurinae. It was then likely later duplicated to a microchromosome containing the BAC sequence Pv150_H19, while the original microchromosome copy of the BAC Pv03_L07 has been lost in the ancestor of P. vitticeps (Figure 3). Since nearly half of the BAC Pv03_L07 consists of mobile elements, another explanation of the co-occurrence of this BAC signal in the microchromosomes could be as a result of the propagation of these mobile elements. The co-occurrence of both sequences in the ZW sex microchromosomes in P. vitticeps is thus likely a result of a rather complex history of rearrangements [59]. Future investigations that include more agamid lizards will better test the proposition that the reconstruction of events suggested here was important for the establishment of cytogenetically distinguishable sex chromosomes in P. vitticeps and its relatives.

Author Contributions: T.E. and S.M.I.A. conceptualized the study. M.A., T.P., S.M.I.A., M.R. and L.K. prepared different chromosome samples. S.M.I.A., T.P., T.G. and S.V.N. conducted field works. S.M.I.A. did the cytogenetic experimentations. S.M.I.A. and T.E. designed and co-drafted the manuscript. T.E., A.G. and S.D.S. supervised S.M.I.A. All authors contributed to reviewing and editing the manuscript. All authors have read and agreed to the published version of the manuscript.

Funding: S.M.I.A. is supported by the International Research Training Program-Higher Degree by Research (RTP-HDR) Scholarship of the University of Canberra. The work was supported in part by a grant from the Australian Research Council (DP170101147) awarded to A.G., T.E. and S.D.S. T. lineata animals were provided for this work as part of Australian Research Council grant (LP110200029) awarded to S.D.S., T.E. and A.G. The Fellowship of Capacity Building for Kasetsart University on Internationalization at Kasetsart University awarded to T.P. and K.S. M.R. was supported by Charles University projects PRIMUS/SCI/46, M.A. and M.R. from Charles University Research Centre program (204069). L.K., M.A. and M.R. were supported by Czech Science Foundation project No. 20-27236J.

Acknowledgments: Thanks to Dianne Gleeson for her comments on the initial draft of the manuscript.

Conflicts of Interest: The authors declare no conflict of interest.

\section{References}

1. Alam, S.M.I.; Sarre, S.D.; Gleeson, D.; Georges, A.; Ezaz, T. Did lizards follow unique pathways in sex chromosome evolution? Genes 2018, 9, 239. [CrossRef] [PubMed]

2. Ezaz, T.; Sarre, S.D.; O’Meally, D.; Graves, J.A.; Georges, A. Sex chromosome evolution in lizards: Independent origins and rapid transitions. Cytogenet. Genome Res. 2009, 127, 249-260. [CrossRef] [PubMed]

3. Valenzuela, N.; Lance, V. Temperature-Dependent Sex Determination in Vertebrates; Smithsonian Books: Washington, DC, USA, 2004.

4. Olmo, E.; Signorino, G. Chromorep: A Reptile Chromosomes Database. Available online: www.chromorep. univpm.it (accessed on 30 March 2018).

5. Ezaz, T.; Srikulnath, K.; Graves, J.A.M. Origin of amniote sex chromosomes: An ancestral super-sex chromosome, or common requirements? J. Hered. 2017, 108, 94-105. [CrossRef] [PubMed]

6. Uetz, P.; Freed, P.; Hošek, J. The Reptile Database. Available online: http://reptile-database.org (accessed on 14 February 2020).

7. Ezaz, T.; Quinn, A.E.; Sarre, S.D.; O’Meally, D.; Georges, A.; Graves, J.A.M. Molecular marker suggests rapid changes of sex-determining mechanisms in Australian dragon lizards. Chromosome Res. 2009, 17, 91-98. [CrossRef]

8. Deakin, J.E.; Ezaz, T. Understanding the evolution of reptile chromosomes through applications of combined cytogenetics and genomics approaches. Cytogenet. Genome Res. 2019, 157, 7-20. [CrossRef] 
9. Deakin, J.E.; Potter, S.; O’Neill, R.; Ruiz-Herrera, A.; Cioffi, M.B.; Eldridge, M.D.; Fukui, K.; Marshall Graves, J.A.; Griffin, D.; Grutzner, F. Chromosomics: Bridging the gap between genomes and chromosomes. Genes 2019, 10, 627. [CrossRef]

10. Deakin, J.E.; Ezaz, T. Tracing the evolution of amniote chromosomes. Chromosoma 2014, 123, $201-216$. [CrossRef]

11. O’Meally, D.; Ezaz, T.; Georges, A.; Sarre, S.D.; Graves, J.A.M. Are some chromosomes particularly good at sex? Insights from amniotes. Chromosome Res. 2012, 20, 7-19. [CrossRef]

12. Matsubara, K.; Tarui, H.; Toriba, M.; Yamada, K.; Nishida-Umehara, C.; Agata, K.; Matsuda, Y. Evidence for different origin of sex chromosomes in snakes, birds, and mammals and step-wise differentiation of snake sex chromosomes. Proc. Natl. Acad. Sci. USA 2006, 103, 18190-18195. [CrossRef]

13. Ezaz, T.; Moritz, B.; Waters, P.; Marshall Graves, J.A.; Georges, A.; Sarre, S.D. The ZW sex microchromosomes of an Australian dragon lizard share no homology with those of other reptiles or birds. Chromosome Res. 2009, 17, 965-973. [CrossRef]

14. Kawai, A.; Ishijima, J.; Nishida, C.; Kosaka, A.; Ota, H.; Kohno, S.-I.; Matsuda, Y. The ZW sex chromosomes of Gekko hokouensis (Gekkonidae, Squamata) represent highly conserved homology with those of avian species. Chromosoma 2009, 118, 43-51. [CrossRef] [PubMed]

15. Alföldi, J.; di Palma, F.; Grabherr, M.; Williams, C.; Kong, L.; Mauceli, E.; Russell, P.; Lowe, C.B.; Glor, R.E.; Jaffe, J.D.; et al. The genome of the green anole lizard and a comparative analysis with birds and mammals. Nature 2011, 477, 587-591. [CrossRef] [PubMed]

16. Srikulnath, K.; Matsubara, K.; Uno, Y.; Nishida, C.; Olsson, M.; Matsuda, Y. Identification of the linkage group of the $\mathrm{Z}$ sex chromosomes of the sand lizard (Lacerta agilis, Lacertidae) and elucidation of karyotype evolution in lacertid lizards. Chromosoma 2014, 123, 563-575. [CrossRef] [PubMed]

17. Srikulnath, K.; Nishida, C.; Matsubara, K.; Uno, Y.; Thongpan, A.; Suputtitada, S.; Apisitwanich, S.; Matsuda, Y. Karyotypic evolution in squamate reptiles: Comparative gene mapping revealed highly conserved linkage homology between the butterfly lizard (Leiolepis reevesii rubritaeniata, Agamidae, Lacertilia) and the Japanese four-striped rat snake (Elaphe quadrivirgata, Colubridae, Serpentes). Chromosome Res. 2009, 17, 975-986. [PubMed]

18. Srikulnath, K.; Uno, Y.; Nishida, C.; Matsuda, Y. Karyotype evolution in monitor lizards: Cross-species chromosome mapping of cDNA reveals highly conserved synteny and gene order in the Toxicofera clade. Chromosome Res. 2013, 21, 805-819. [CrossRef] [PubMed]

19. Harlow, P. Temperature-dependent sex determination in lizards. In Temperature-Dependent Sex Determination in Vertebrates; Valenzuela, N., Lance, V., Eds.; Smithsonian Books: Washington, DC, USA, 2004; pp. 42-52.

20. Ezaz, T.; Quinn, A.E.; Miura, I.; Sarre, S.D.; Georges, A.; Graves, J.A.M. The dragon lizard Pogona vitticeps has ZZ/ZW micro-sex chromosomes. Chromosome Res. 2005, 13, 763-776. [CrossRef]

21. Harlow, P.S. The Ecology of Sex-Determining Mechanisms in Australian Agamid Lizards. Ph.D. Thesis, Macquarie University, Sydney, Australia, 2001.

22. Holleley, C.E.; O’Meally, D.; Sarre, S.D.; Graves, J.A.M.; Ezaz, T.; Matsubara, K.; Azad, B.; Zhang, X.; Georges, A. Sex reversal triggers the rapid transition from genetic to temperature-dependent sex. Nature 2015, 523, 79-82. [CrossRef]

23. Quinn, A.E.; Georges, A.; Sarre, S.D.; Guarino, F.; Ezaz, T.; Graves, J.A.M. Temperature sex reversal implies sex gene dosage in a reptile. Science 2007, 316, 411. [CrossRef]

24. Pyron, R.A.; Burbrink, F.T.; Wiens, J.J. A phylogeny and revised classification of Squamata, including 4161 species of lizards and snakes. BMC Evol. Biol. 2013, 13, 93. [CrossRef]

25. Zheng, Y.; Wiens, J.J. Combining phylogenomic and supermatrix approaches, and a time-calibrated phylogeny for squamate reptiles (lizards and snakes) based on 52 genes and 4162 species. Mol. Phylogenet. Evol. 2016, 94, 537-547. [CrossRef]

26. Rovatsos, M.; Altmanová, M.; Johnson Pokorná, M.; Velenský, P.; Sánchez Baca, A.; Kratochvíl, L. Evolution of karyotypes in chameleons. Genes 2017, 8, 382. [CrossRef] [PubMed]

27. Nielsen, S.V.; Banks, J.L.; Diaz, R.E.; Trainor, P.A.; Gamble, T. Dynamic sex chromosomes in Old World chameleons (Squamata: Chamaeleonidae). J. Evol. Biol. 2018, 31, 484-490. [CrossRef] [PubMed]

28. Altmanová, M.; Rovatsos, M.; Johnson Pokorná, M.; Veselý, M.; Wagner, F.; Kratochvíl, L. All iguana families with the exception of basilisks share sex chromosomes. Zoology 2018, 126, 98-102. [CrossRef] [PubMed] 
29. Nielsen, S.V.; Guzmán-Méndez, I.A.; Gamble, T.; Blumer, M.; Pinto, B.J.; Kratochvíl, L.; Rovatsos, M. Escaping the evolutionary trap? Sex chromosome turnover in basilisks and related lizards (Corytophanidae: Squamata). Biol. Lett. 2019, 15, 20190498. [CrossRef] [PubMed]

30. Hugall, A.F.; Foster, R.; Hutchinson, M.; Lee, M.S.Y. Phylogeny of Australasian agamid lizards based on nuclear and mitochondrial genes: Implications for morphological evolution and biogeography. Biol. J. Linn. Soc. 2008, 93, 343-358. [CrossRef]

31. Grismer, J.L.; Bauer, A.M.; Grismer, L.L.; Thirakhupt, K.; Aowphol, A.; Oaks, J.R.; Wood, P.L., Jr.; Onn, C.K.; Thy, N.; Cota, M.; et al. Multiple origins of parthenogenesis, and a revised species phylogeny for the Southeast Asian butterfly lizards, Leiolepis. Biol. J. Linn. Soc. 2014, 113, 1080-1093. [CrossRef]

32. Miller, K.L.; Rico, S.C.; Muletz-Wolz, C.R.; Campana, M.G.; McInerney, N.; Augustine, L.; Frere, C.; Peters, A.M.; Fleischer, R.C. Parthenogenesis in a captive Asian water dragon (Physignathus cocincinus) identified with novel microsatellites. PLoS ONE 2019, 14, e0217489. [CrossRef]

33. Blackburn, D.G. Evolutionary origins of viviparity in the Reptilia. I. Sauria. Amphibia-Reptilia 1982, 3, $185-205$. [CrossRef]

34. Nakhasi, U. Karyotypic homology and evolution of the Agamid lizards. Cytologia 1980, 45, 211-219.

35. Witten, G.J. Some karyotypes of Australian agamids (Reptilia: Lacertilia). Aust. J. Zool. 1983, 31, 533-540. [CrossRef]

36. Adegoke, J. Studies on the chromosomes of the rainbow lizard Agama agama agama (L.) with notes on polypoidy in the spermatocytes. Cytologia 1988, 53, 233-239. [CrossRef]

37. Viets, B.E.; Ewert, M.A.; Talent, L.G.; Nelson, C.E. Sex-determining mechanisms in squamate reptiles. J. Exp. Zool. 1994, 270, 45-56. [CrossRef]

38. Henle, K. A brief review of the origin and use of 'stellio' in herpetology and a comment on the nomenclature and taxonomy of agamids of the genus Agama (sensu lato). Herpetozoa 1995, 8, 3-9.

39. Zeng, X.M.; Wang, Y.Z.; Liu, Z.J.; Fang, Z.L.; Wu, G.F. Karyotypes on nine species in the genus Phrynocephalus, with discussion of karyotypic evolution of Chinese Phrynocephalus. Acta. Zool. Sin. 1997, 43, 399-410.

40. Kritpetcharat, O.; Kritpetcharat, C.; Luangpirom, A.; Watcharanon, P. Karyotype of four Agamidae species from the Phu Phan national park in Thailand. Sci. Asia 1999, 25, 185-188. [CrossRef]

41. Pokorná, M.; Kratochvíl, L. Phylogeny of sex-determining mechanisms in squamate reptiles: Are sex chromosomes an evolutionary trap? Zool. J. Linn. Soc. 2009, 156, 168-183. [CrossRef]

42. Srikulnath, K.; Uno, Y.; Matsubara, K.; Thongpan, A.; Suputtitada, S.; Apisitwanich, S.; Nishida, C.; Matsuda, Y. Chromosomal localization of the 18S-28S and 5S rRNA genes and (TTAGGG)n sequences of butterfly lizards (Leiolepis belliana belliana and Leiolepis boehmei, Agamidae, Squamata). Genet. Mol. Biol. 2011, 34, 583-586. [CrossRef]

43. Baig, K.J.; Wagner, P.; Ananjeva, N.B.; Boehme, W. A morphology-based taxonomic revision of Laudakia Gray, 1845 (Squamata: Agamidae). Vertebr. Zool. 2012, 62, 213-260.

44. Inamdar Doddamani, L.S.; Vani, V.; Seshagiri, P.B. A tropical oviparous lizard, Calotes versicolor, exhibiting a potentially novel FMFM pattern of temperature-dependent sex determination. J. Exp. Zool. A Ecol. Genet. Physiol. 2012, 317, 32-46. [CrossRef]

45. Phimphan, S.; Tanomtong, A.; Patawang, I.; Kaewsri, S.; Jantarat, S.; Sanoamuang, L.O. Cytogenetic Study of Northeastern Butterfly Lizard, Leiolepis reevesii rubritaeniata (Squamata, Agamidae) in Northeast Thailand. Cytologia 2013, 78, 133-140. [CrossRef]

46. Utong, J.A.M.; Abukashawa, S.M.A. Characterization of the agamid lizard genus Uromastyx from Eastern Sudan based on morphology, karyotypes and mitochondrial DNA. Asian. Herpetol. Res. 2013, 4, $268-281$.

47. Gamble, T.; Coryell, J.; Ezaz, T.; Lynch, J.; Scantlebury, D.P.; Zarkower, D. Restriction site-associated DNA sequencing (RAD-seq) reveals an extraordinary number of transitions among gecko sex-determining systems. Mol. Biol. Evol. 2015, 32, 1296-1309. [CrossRef] [PubMed]

48. Grismer, J.L.; Grismer, L.L. Who's your mommy? Identifying maternal ancestors of asexual species of Leiolepis Cuvier, 1829 and the description of a new endemic species of asexual Leiolepis Cuvier, 1829 from Southern Vietnam. Zootaxa 2010, 2433, 47-61. [CrossRef]

49. Midtgaard, R. RepFocus-A Survey of the Reptiles of the World; 1st ed.; E-book Published by the Author, Middelfart, Denmark. 2019. Available online: www.repfocus.dk/Agamidae.html (accessed on 14 April 2020).

50. Pokorná, M.; Altmanová, M.; Kratochvíl, L. Multiple sex chromosomes in the light of female meiotic drive in amniote vertebrates. Chromosome Res. 2014, 22, 35-44. [CrossRef] [PubMed] 
51. Quinn, A.; Georges, A.; Sarre, S.; Guarino, F.; Ezaz, T.; Graves, J. Sex chromosomes and incubation temperature interact to determine sex of a reptile. IAHS Proc. Rep. 2007, 316, 411.

52. Sarre, S.D.; Georges, A.; Quinn, A. The ends of a continuum: Genetic and temperature-dependent sex determination in reptiles. BioEssays 2004, 26, 639-645. [CrossRef]

53. Georges, A.; Ezaz, T.; Quinn, A.E.; Sarre, S.D. Are reptiles predisposed to temperature-dependent sex determination? Sex. Dev. 2010, 4, 7-15. [CrossRef]

54. Janes, D.E.; Organ, C.L.; Fujita, M.K.; Shedlock, A.M.; Edwards, S.V. Genome evolution in Reptilia, the sister group of mammals. Ann. Rev. Genomics. Hum. Genet. 2010, 11, 239-264. [CrossRef]

55. O'Meally, D. Evolution of Reptile Sex Chromosomes. Ph.D. Thesis, The Australian National University, Canberra, Australia, 2010.

56. Ezaz, T.; Azad, B.; O’Meally, D.; Young, M.J.; Matsubara, K.; Edwards, M.J.; Zhang, X.; Holleley, C.E.; Deakin, J.E.; Graves, J.A.M.; et al. Sequence and gene content of a large fragment of a lizard sex chromosome and evaluation of candidate sex differentiating gene R-spondin 1. BMC Genomics 2013, 14, 899. [CrossRef]

57. Domaschenz, R.; Livernois, A.M.; Rao, S.; Ezaz, T.; Deakin, J.E. Immunofluorescent staining reveals hypermethylation of microchromosomes in the central bearded dragon, Pogona vitticeps. Mol. Cytogenet. 2015, 8, 104. [CrossRef]

58. Young, M.J.; O’Meally, D.; Sarre, S.D.; Georges, A.; Ezaz, T. Molecular cytogenetic map of the central bearded dragon, Pogona vitticeps (Squamata: Agamidae). Chromosome Res. 2013, 21, 361-374. [CrossRef] [PubMed]

59. Deakin, J.E.; Edwards, M.J.; Patel, H.; O’Meally, D.; Lian, J.; Stenhouse, R.; Ryan, S.; Livernois, A.M.; Azad, B.; Holleley, C.E.; et al. Anchoring genome sequence to chromosomes of the central bearded dragon (Pogona vitticeps) enables reconstruction of ancestral squamate macrochromosomes and identifies sequence content of the $\mathrm{Z}$ chromosome. BMC Genomics 2016, 17, 447. [CrossRef] [PubMed]

60. Georges, A.; Li, Q.; Lian, J.; O’Meally, D.; Deakin, J.; Wang, Z.; Zhang, P.; Fujita, M.; Patel, H.R.; Holleley, C.E.; et al. High-coverage sequencing and annotated assembly of the genome of the Australian dragon lizard Pogona vitticeps. GigaScience 2015, 4, 45. [CrossRef] [PubMed]

61. Matsubara, K.; O’Meally, D.; Sarre, S.D.; Georges, A.; Srikulnath, K.; Ezaz, T. ZW sex chromosomes in Australian dragon lizards (Agamidae) originated from a combination of duplication and translocation in the nucleolar organising region. Genes 2019, 10, 861. [CrossRef] [PubMed]

62. Srikulnath, K.; Azad, B.; Singchat, W.; Ezaz, T. Distribution and amplification of interstitial telomeric sequences (ITSs) in Australian dragon lizards support frequent chromosome fusions in Iguania. PLoS ONE 2019, 14, e0212683. [CrossRef] [PubMed]

63. Ezaz, T.; O’Meally, D.; Quinn, A.E.; Sarre, S.D.; Georges, A.; Graves, J.A.M. A simple non-invasive protocol to establish primary cell lines from tail and toe explants for cytogenetic studies in Australian dragon lizards (Squamata: Agamidae). Cytotechnology 2008, 58, 135-139. [CrossRef] [PubMed]

64. Chaiprasertsri, N.; Uno, Y.; Peyachoknagul, S.; Prakhongcheep, O.; Baicharoen, S.; Charernsuk, S.; Nishida, C.; Matsuda, Y.; Koga, A.; Srikulnath, K. Highly species-specific centromeric repetitive DNA sequences in lizards: Molecular cytogenetic characterization of a novel family of satellite DNA sequences isolated from the water monitor lizard (Varanus salvator macromaculatus, Platynota). J. Hered. 2013, 104, 798-806. [CrossRef]

65. Mazzoleni, S.; Augstenová, B.; Clemente, L.; Auer, M.; Fritz, U.; Praschag, P.; Protiva, T.; Velenský, P.; Kratochvíl, L.; Rovatsos, M. Turtles of the genera Geoemyda and Pangshura (Testudines: Geoemydidae) lack differentiated sex chromosomes: The end of a 40-year error cascade for Pangshura. PeerJ 2019, 7, e6241. [CrossRef]

66. Townsend, T.M.; Mulcahy, D.G.; Noonan, B.P.; Sites, J.W., Jr.; Kuczynski, C.A.; Wiens, J.J.; Reeder, T.W. Phylogeny of iguanian lizards inferred from 29 nuclear loci, and a comparison of concatenated and species-tree approaches for an ancient, rapid radiation. Mol. Phylogenet. Evol. 2011, 61, 363-380. [CrossRef]

67. Voss, S.R.; Kump, D.K.; Putta, S.; Pauly, N.; Reynolds, A.; Henry, R.J.; Basa, S.; Walker, J.A.; Smith, J.J. Origin of amphibian and avian chromosomes by fission, fusion, and retention of ancestral chromosomes. Genome Res. 2011, 21, 1306-1312. [CrossRef]

68. Iannucci, A.; Altmanová, M.; Ciofi, C.; Ferguson-Smith, M.; Milan, M.; Pereira, J.C.; Pether, J.; Rehák, I.; Rovatsos, M.; Stanyon, R.; et al. Conserved sex chromosomes and karyotype evolution in monitor lizards (Varanidae). Heredity 2019, 123, 215-227. [CrossRef] [PubMed] 
69. Barby, F.F.; Bertollo, L.A.C.; de Oliveira, E.A.; Yano, C.F.; Hatanaka, T.; Ráb, P.; Sember, A.; Ezaz, T.; Artoni, R.F.; Liehr, T.; et al. Emerging patterns of genome organization in Notopteridae species (Teleostei, Osteoglossiformes) as revealed by Zoo-FISH and Comparative Genomic Hybridization (CGH). Sci. Rep. 2019, 9, 1112. [CrossRef] [PubMed]

70. Cioffi, M.B.; Ráb, P.; Ezaz, T.; Bertollo, L.A.C.; Lavoué, S.; Oliveira, E.A.; Sember, A.; Molina, W.F.; Souza, F.H.S.; Majtánová, Z.; et al. Deciphering the evolutionary history of arowana fishes (Teleostei, Osteoglossiformes, Osteoglossidae): Insight from comparative cytogenomics. Int. J. Mol. Sci. 2019, 20, 4296. [CrossRef] [PubMed]

71. Kasai, F.; Garcia, C.; Arruga, M.; Ferguson-Smith, M. Chromosome homology between chicken (Gallus gallus domesticus) and the red-legged partridge (Alectoris rufa); evidence of the occurrence of a neocentromere during evolution. Cytogenet. Genome Res. 2003, 102, 326-330. [CrossRef]

72. Shibusawa, M.; Nishida-Umehara, C.; Masabanda, J.; Griffin, D.K.; Isobe, T.; Matsuda, Y. Chromosome rearrangements between chicken and guinea fowl defined by comparative chromosome painting and FISH mapping of DNA clones. Cytogenet. Genome Res. 2002, 98, 225-230. [CrossRef]

73. Shetty, S.; Griffin, D.K.; Graves, J.A.M. Comparative painting reveals strong chromosome homology over 80 million years of bird evolution. Chromosome Res. 1999, 7, 289-295. [CrossRef]

74. Montiel, E.E.; Badenhorst, D.; Lee, L.S.; Literman, R.; Trifonov, V.; Valenzuela, N. Cytogenetic insights into the evolution of chromosomes and sex determination reveal striking homology of turtle sex chromosomes to amphibian autosomes. Cytogenet. Genome Res. 2016, 148, 292-304. [CrossRef]

(C) 2020 by the authors. Licensee MDPI, Basel, Switzerland. This article is an open access article distributed under the terms and conditions of the Creative Commons Attribution (CC BY) license (http://creativecommons.org/licenses/by/4.0/). 